\title{
Rare cause of gastric outlet obstruction: xanthogranulomatous cholecystitis
}

\author{
Gaurav Garg, ${ }^{1}$ Kamal Kataria, ${ }^{2}$ Nupur Bansal, ${ }^{3}$ Iqbal Singh ${ }^{4}$
}

'Department of Urology, King George's Medical University, Lucknow, India

${ }^{2}$ Department of Surgery, All India Institute of Medical Sciences, New Delhi, India ${ }^{3}$ Department of Radiotherapy, King George's Medical University, Lucknow, India ${ }^{4}$ Department of Surgery, Urology Division, University College of Medical Sciences, New Delhi, India

Correspondence to Dr Gaurav Garg, gougarg@gmail.com

Accepted 25 August 2018

\section{DESCRIPTION}

A 62-year-old Indian female patient presented with right upper quadrant pain and multiple episodes of vomiting for 10 days. She denied history of fever, jaundice, past anorexia/weight loss and previous surgeries. She was dehydrated, tachycardia (120/ min) was present, and there was tenderness in the right upper quadrant. Routine investigations revealed presence of anaemia (haemoglobin $9.1 \mathrm{~g} /$ $\mathrm{dL})$, raised total leucocyte counts $\left(17 \times 10^{\wedge}\right.$ 9/L) and hypokalaemia $(2.8 \mathrm{mEq} / \mathrm{L})$. All other blood tests (liver function/kidney function/blood sugar and coagulation profile) were normal. Patient was stabilised with intravenous fluids, antibiotics and other supportive management. Imaging with ultrasound (USG) was suboptimal due to the massive intestinal gas and uncooperative nature of the patient. A collapsed gallbladder (GB) and a mass with a smooth curvilinear surface and posterior acoustic shadowing in the distal part of the duodenum were the only distinguishable findings. Due to repeated episodes of vomiting, the patient underwent an upper gastrointestinal endoscopy, which was suggestive of pyloric obstruction. For the further evaluation of GB mass in the USG report, the patient underwent an abdominal CT examination. Non-enhanced axial CT images revealed mass-like thickening of the GB wall (maximum thickness $18 \mathrm{~mm}$ ) with multiple intramural hypoattenuated nodules (figure 1); the postcontrast images showed luminal surface enhancement at the lesion

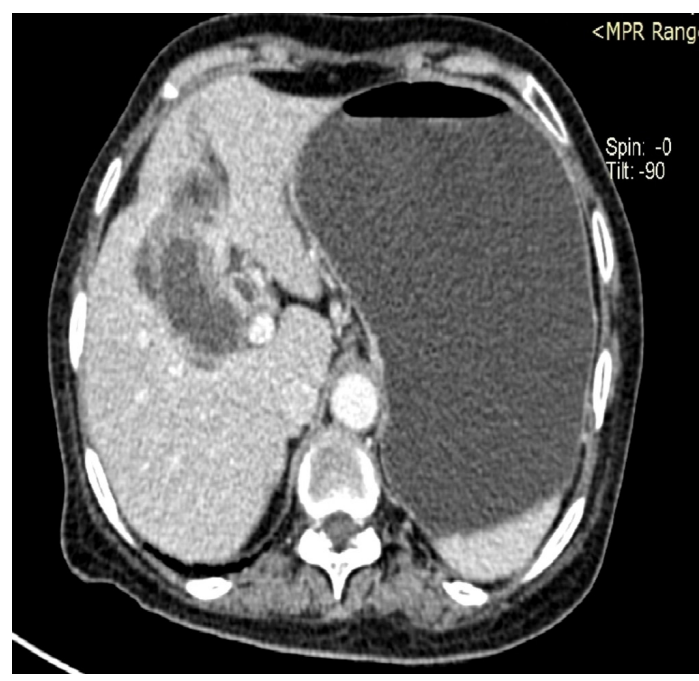

Figure 1 Non-enhanced axial CT images revealed mass-like thickening of the gallbladder wall with multiple intramural hypoattenuated nodules.

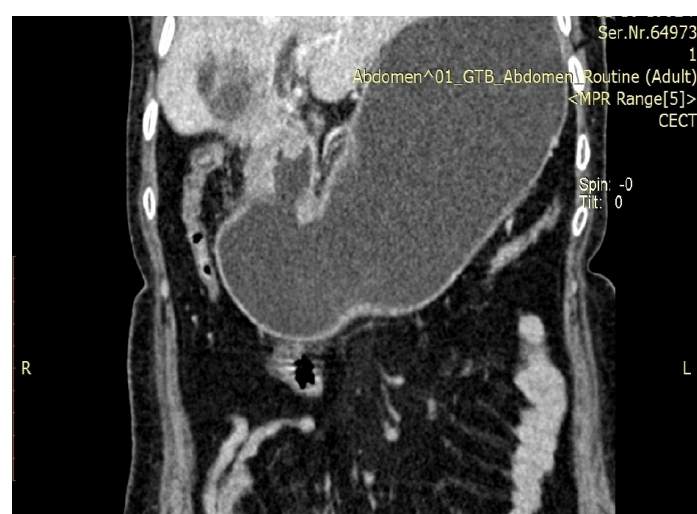

Figure 2 Postcontrast CT scan images showing thickening and inflammation in antropyloric region and first part of the duodenum.

site and focal discontinuity at some places. Additionally, there was thickening and inflammation noted in the antropyloric region and the first part of the duodenum (figure 2). Due to the persisting upper gastrointestinal tract obstruction, surgery was planned on the seventh day from the admission. Intraoperatively, the GB mass was adherent to the duodenum and colon, there was thickening and narrowing present at the gastric outlet obstruction. The decompressed and oedematous GB was seen to be fistulised to the second part of the duodenum. The patient underwent partial cholecystectomy, primary repair of fistula over a T-tube and retrocolic gastrojejunostomy. Histopathological examination of the GB came out to be xanthogranulomatous cholecystitis (XGC) (figure 3). The patient had an uneventful postoperative recovery. She is doing fine at 3 months follow-up. XGC is a rare form of

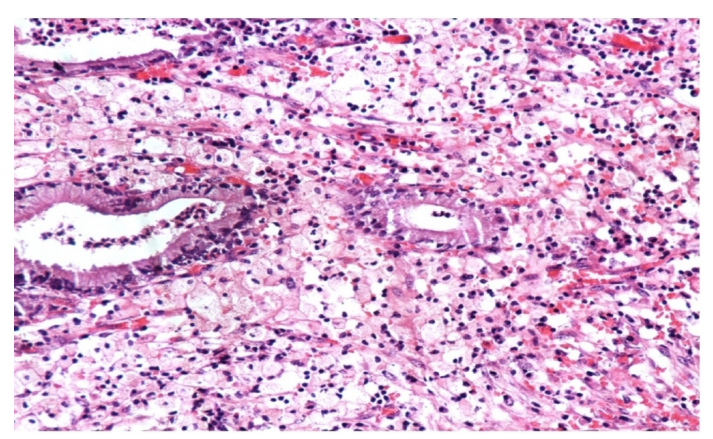

Figure $3 \quad H \& E(x 200)$ image showing thickened gallbladder wall with inflammatory infiltrate; composed predominantly of foamy macrophages, admixed with lymphocytes, plasma cells and few neutrophils. 
chronic cholecystitis and predominantly seen in women between the ages of 60 and 70 years. ${ }^{1}$ The clinical presentation of XGC resembles acute or chronic cholecystitis and it mimics GB cancer macroscopically and on imaging, until it is proved by histological diagnosis. ${ }^{2}$ Direct involvement of extra GB organs and structures is not common. ${ }^{3}$ The most common sequelae include perforation, abscess formation, fistulous tracts and extension of the inflammatory process to the surrounding structures. ${ }^{3}$ Our patient was a woman who had a history of worsening nausea, vomiting and tenderness at the right upper quadrant. However, neither findings on physical examination nor results of laboratory tests appeared to be useful in the differential diagnosis of XGC among other more frequent cholecystitis types or GB carcinoma. Although the aetiology of XGC is still not clear, some studies have reported that the extravasation of bile into the GB wall is believed to initiate the development of the inflammatory process. ${ }^{3} \mathrm{XGC}$ is often mistaken for GB carcinoma. However, in few studies, a positive association between XGC and carcinoma of the GB has been reported. ${ }^{3} 4$ The differential diagnosis of XGC and GB adenocarcinoma/cholangiocarcinoma is very difficult. ${ }^{5}$ The clinical presentation can be similar, and in patients with XGC, the CA19-9 (carbohydrate antigen 19-9) can be normal or elevated. ${ }^{5}$ It is also difficult to differentiate these conditions with ultrasound, CT and MRI imaging. ${ }^{6}$ The role of frozen sections is also important and they should always be performed. However, in cases showing extensive invasion of extra GB organs, the surgical strategy should not be determined

Learning points

Xanthogranulomatous cholecystitis (XGC) can mimic gallbladder carcinoma on clinical examination and imaging.

- XGC can rarely present with gastric outlet obstruction.

- Diagnosis of XGC can be made on histopathological examination only. only by frozen section examination since it can give false negative results. ${ }^{7-9}$ The purpose of this manuscript is to highlight the fact that preoperative and intraoperative differential diagnosis of XGC from GB carcinoma remains a challenge when it is associated with inflammatory involvement of surrounding tissues, and XGC can present as one of the rare causes of gastric outlet obstruction.

Contributors KK, GG: concept, design, supervision, processing, writing manuscript and critical analysis. NB: supervision, processing, writing manuscript and critical analysis. IS: concept, supervision, writing manuscript and critical analysis.

Funding The authors have not declared a specific grant for this research from any funding agency in the public, commercial or not-for-profit sectors.

Competing interests None declared.

Patient consent Obtained.

Provenance and peer review Not commissioned; externally peer reviewed.

\section{REFERENCES}

1 Benbow EW. Xanthogranulomatous cholecystitis. Br J Surg 1990;77:255-6.

2 Guzmán-Valdivia G. Xanthogranulomatous cholecystitis: 15 years' experience. World J Surg 2004;28:254-7.

3 Houston JP, Collins MC, Cameron I, et al. Xanthogranulomatous cholecystitis. Br J Surg 1994:81:1030-2.

4 Levy AD, Murakata LA, Abbott RM, et al. From the archives of the AFIP. Benign tumors and tumorlike lesions of the gallbladder and extrahepatic bile ducts: radiologic-pathologic correlation. Armed forces institute of pathology. Radiographics 2002;22:387-413

5 Yoshida J, Chijiiwa K, Shimura $\mathrm{H}$, et al. Xanthogranulomatous cholecystitis versus gallbladder cancer: clinical differentiating factors. Am Surg 1997;63:367-71.

6 Chun KA, Ha HK, Yu ES, et al. Xanthogranulomatous cholecystitis: CT features with emphasis on differentiation from gallbladder carcinoma. Radiology 1997;203:93-7.

7 Spinelli A, Schumacher G, Pascher A, et al. Extended surgical resection for xanthogranulomatous cholecystitis mimicking advanced gallbladder carcinoma: a case report and review of literature. World J Gastroenterol 2006;12:2293-6.

8 Rastogi A, Singh DK, Sakhuja P, et al. Florid xanthogranulomatous cholecystitis masquerading as invasive gallbladder cancer leading to extensive surgical resection. Indian J Pathol Microbiol 2010;53:144-7.

9 Aoki T, Tsuchida A, Kasuya K, et al. Is frozen section effective for diagnosis of unsuspected gallbladder cancer during laparoscopic cholecystectomy? Surg Endosc 2002;16:197-200.

Copyright 2018 BMJ Publishing Group. All rights reserved. For permission to reuse any of this content visit

http://group.bmj.com/group/rights-licensing/permissions.

BMJ Case Report Fellows may re-use this article for personal use and teaching without any further permission.

Become a Fellow of BMJ Case Reports today and you can:

- Submit as many cases as you like

- Enjoy fast sympathetic peer review and rapid publication of accepted articles

- Access all the published articles

- Re-use any of the published material for personal use and teaching without further permission

For information on Institutional Fellowships contact consortiasales@bmjgroup.com

Visit casereports.bmj.com for more articles like this and to become a Fellow 